\section{Problems in the Interpretation of Serological Results of Hepatitis B Testing During an Incident of Hepatitis B Virus Reactivation in a Dialysis Unit}

TO THE EDIT OR-In April 2005, a case of reactivation of hepatitis $B$ virus (HBV) infection occurred in a hemodialysis patient in an Irish tertiary referral center. ${ }^{1}$ In the absence of specific Irish dialysis guidelines at this time, most Irish units, including this center, followed UK guidelines; that is, HBV surface antigen (HBsAg) testing was performed prior to dialysis and then monthly, ideally, but at least every 3 months. ${ }^{2}$ The majority of units did not test for $\mathrm{HBV}$ core antibody (anti-HBc). This patient had tested negative for HBsAg prior to dialysis in November 2004 and was found to be $\mathrm{HBsAg}$ positive in April 2005. The patient became immunosuppressed over this period. Testing of an archived sample obtained prior to dialysis (November 2004) revealed that it was positive for anti-HBc. The April 2005 sample was positive for anti-HBc and negative for anti- $\mathrm{HBc}$ immunoglobulin (Ig) $\mathrm{M}$.

Not all patients at the dialysis center had been vaccinated against $\mathrm{HBV}$, and the results of serological testing for $\mathrm{HBV}$ could not be retrieved in a timely manner because results were manually recorded. As the patient was potentially infectious over a 5-month period, 306 patients who had attended 17 different dialysis centers and undergone dialysis in the index center during this period were included. A program of $\mathrm{HBV}$ vaccination and serological testing was instituted; patients were tested for HBsAg weekly for 12 weeks from the date of the last dialysis procedure that occurred at the index hospital within the exposure period, ${ }^{2}$ and they were also tested for anti-HBc. If these samples were anti-HBc positive, then samples archived prior to November 2004 were also tested for anti-HBc. Two hundred ninety-two of 306 patients were tested in a single laboratory. No patient acquired hepatitis $B$ during the follow-up period. However, HBV testing during this investigation presented practical problems for the management of the following 3 patient groups: (1) dialysis patients with weak-positive HBsAg results, (2) patients whose results were anti- $\mathrm{HBc}$ positive and/or $\mathrm{HBsAg}$ negative, and (3) patients who had recently received blood products.

A total of 7 patients had 10 weak-positive HBsAg results, which were subsequently confirmed to be the result of recent receipt of $\mathrm{HBV}$ vaccine. All weak-positive $\mathrm{HBsAg}$ results occurred within 13 days of $\mathrm{HBV}$ vaccination, with 8 occurring in the first 5 days. Although transient weak-positive HBsAg results after vaccination have been reported previously, ${ }^{3,4}$ these results presented specific challenges during this partic- ular incident, during which we were using $\mathrm{HBsAg}$ as a marker for $\mathrm{HBV}$ infection. At the time, it was not possible to ascertain whether a weak-positive $\mathrm{HBsAg}$ result represented $\mathrm{HBV}$ seroconversion, a false-positive result, or a vaccine-related weak-positive result. Patients with weak-positive $\mathrm{HBsAg}$ results were segregated and received dialysis on dedicated machines until a negative $\mathrm{HBsAg}$ test result was obtained on follow-up testing. This caused concern to both patients and dialysis staff, and it put pressure on the day-to-day operations in the affected dialysis units because of a lack of spare dialysismachine capacity. In all cases, follow-up serological testing was negative for both $\mathrm{HBsAg}$ and anti-HBc.

Of the 292 patients tested in our laboratory, 10 (3.4\%) had serological evidence of past $\mathrm{HBV}$ infection (ie, HBsAg negative and/or anti-HBc positive test results). This issue is not addressed in the current UK guidelines. ${ }^{2}$ However, the US guidelines clearly state that isolation of these patients is not necessary once the $\mathrm{HBsAg}$ result remains negative. ${ }^{5}$ Neither set of guidelines provided useful advice on follow-up $\mathrm{HBs} A g$ testing for these patients or on DNA testing. As was the case with the index patient, these patients' $\mathrm{HBV}$ infections could potentially be reactivated, and they could become $\mathrm{HBsAg}$ positive. It was decided not to isolate anti-HBc positive patients once $\mathrm{HBsAg}$ test results remained negative. ${ }^{5}$ In addition, it was agreed that these patients should be tested monthly for $\mathrm{HBsAg}$.

A renal transplantation patient who had received intravenous immunoglobulin therapy had fluctuating anti-HBc results during the testing period (shifting from negative to positive on 2 occasions). After investigation, it was found that immunoglobulin administration coincided with the patient's positive anti- $\mathrm{HBc}$ results. This product is screened for $\mathrm{HBsAg}$, but not for anti-HBc. Screening later confirmed that this dialysis patient was negative for both $\mathrm{HBsAg}$ and anti- $\mathrm{HBc}$, but at the time the management of this patient was a challenge because we could not be sure that this patient had not acquired HBV infection. Dialysis teams should be aware that commercial immunoglobulin preparations are not screened for anti-HBc and that recent administration of immunoglobulin may account for positive anti-HBc test results. We would suggest that such patients have a repeat anti-HBc test 2-3 months after immunoglobulin administration.

Although no cases of $\mathrm{HBV}$ cross-infection were identified, interpretation of HBV serological test results during this investigation posed many practical problems. We would recommend that hemodialysis patients not be screened for $\mathrm{HBsAg}$ for at least 7 days after $\mathrm{HBV}$ vaccination; in addition, the management of hemodialysis patients with weak-positive HBsAg results after vaccination should include follow-up HBsAg testing and discussion with a microbiologist and/or virologist about the significance of the result and the need for segregation or dialysis on a dedicated machine. We wish 
to highlight the potential for confusion in the interpretation of serological results of testing for HBV if patients have received commercial immunoglobulin preparations as outlined above. In addition, we wish to highlight the lack of agreement between international hemodialysis guidelines. At the time of the incident, most Irish units followed UK guidelines ${ }^{2}$ and did not test for anti-HBc. This is in contrast to practice in the United States, where HBsAg and anti-HBc are tested for on admission. ${ }^{5}$ The Irish guidelines were revised in the light of this incident and now recommend anti-HBc testing prior to dialysis. ${ }^{6}$ However, no international guidance addresses the role of $\mathrm{HBV}$ DNA testing for $\mathrm{HBsAg}$-negative, anti- $\mathrm{HBC}$ positive patients and their subsequent management. Centers for Disease Control and Prevention guidelines ${ }^{5}$ address the performance of a single DNA test, but do not comment on the potential cross-infection risk posed by HBV DNA-positive patients, nor do the guidelines recommend follow-up DNA testing of these patients. Occult HBV infection has been detected in dialysis units ${ }^{7,8}$ and transmission has been described in recipients of donated blood and organs. ${ }^{9,10}$ To date there has been no evidence of transmission in dialysis units, but the potential remains.

\section{ACKNOWLEDGMENTS}

Potential conflicts of interest. All authors report no conflicts of interest relevant to this article.

F. Fitzpatrick, MD; M. Crean, MSc; G. Kaminski, MSc; J. Connell, PhD; L. Thornton, MB; N. Murphy, MSc; A. Brennan, MPhil; J. Walsh, MB; H. Humphreys, MD; E. Smyth, MB

From the National Virus Reference Laboratory, University College Dublin (F.F., M.C., G.K., J.C.), the Health Protection Surveillance Centre (L.T., N.M., A.B.), the Departments of Nephrology (J.W.) and Clinical Microbiology (H.H., E.S.), Beaumont Hospital Dublin, and the Royal College of Surgeons in Ireland (H.H.), Dublin, Ireland.

Address reprint requests to Fidelma Fitzpatrick, MD, MRCP, MRCPath, Consultant Microbiologist, Health Protection Surveillance Centre, 25-27 Middle Gardiner Street, Dublin 1, Ireland (fidelma.fitzpatrick@mailx.hse.ie).

Presented in part: Hospital Infection Society International Conference; Amsterdam, The Netherlands; October 2006 (poster P1.07). The national public health management of this incident was published recently: Thornton L, Fitzpatrick F, de la Harpe D, et al. Hepatitis B reactivation in an Irish dialysis unit, 2005. Euro Surveill 2007;12 [Epub ahead of print]. Available online: http://www.eurosurveillance.org/em/v12n04/1204-224.asp.

Infect Control Hosp Epidemiol 2007; 28:1417-1418

(C) 2007 by The Society for Healthcare Epidemiology of America. All rights reserved. 0899-823X/2007/2812-0021\$15.00. DOI: $10.1086 / 524832$

\section{REFERENCES}

1. Thornton L, Fitzpatrick F, de la Harpe D, et al. Hepatitis B reactivation in an Irish dialysis unit, 2005. Euro Surveill 2007; 12 [Epub ahead of print]. Available online: http://www.eurosurveillance.org/em/v12n04/ 1204-224.asp. Accessed October 22, 2007.

2. Department of Health, England. Good practice guidelines for renal di- alysis/transplantation units. Prevention and control of blood-borne virus infection: Recommendations of a Working Group convened by the Public Health Laboratory Service on behalf of the Department of Health. Available at: http://www.dh.gov.uk/en/Publicationsandstatistics/Publications/ PublicationsPolicyAndGuidance/DH_4005752. Accessed October 22, 2007.

3. Janzen L, Minuk GY, Fast M, Bernstein KNJ. Vaccine-induced hepatitis B surface antigen positivity in adult hemodialysis patients: incidental and surveillance data. J Am Soc Nephrol 1996; 7:1228-1234.

4. Ly D, Yee HF Jr, Brezina M, Martin P, Gitnick G, Saab S. Hepatitis B surface antigenemia in chronic hemodialysis patients: effect of hepatitis B immunization. Am J Gastroenterol 2002; 97:138-141.

5. Recommendations for preventing transmission of infections among chronic hemodialysis patients. MMWR Recomm Rep 2001; 50(RR-5): $1-43$.

6. Department of Health and Children, Ireland. The prevention of transmission of blood-borne diseases in the health-care setting. Available at: http://www.dohc.ie/publications/transmission_of_blood_borne_diseases 2006.html. Accessed October 22, 2007.

7. Siagris D, Christofidou M, Triga K, et al. Occult hepatitis B virus infection in hemodialysis patients with chronic HCV infection. J Nephrol 2006; 19:327-333.

8. Minuk GY, Sun DF, Greenberg R, et al. Occult hepatitis B virus infection in a North American adult hemodialysis patient population. Hepatology 2004; 40:1072-1077.

9. Dickson RC, Everhart JE, Lake JR, et al. Transmission of hepatitis B by transplantation of livers from donors positive for antibody to hepatitis $B$ core antigen. The National Institute of Diabetes and Digestive and Kidney Diseases Liver Transplantation Database. Gastroenterology 1997; 113:1668-1674.

10. Hoofnagle JH, Seeff LB, Bales ZB, Zimmermann HJ. Type B hepatitis after transfusion with blood containing antibody to hepatitis B core antigen. $N$ Engl J Med 1978; 298:1379-1383.

\section{Understanding Why Methicillin-Resistant Staphylococcus aureus Control Measures Are Successful in Different Countries}

To the Editor - I read with interest, and no little envy, about the successful efforts of van Trijp and colleagues ${ }^{1}$ in successfully controlling an outbreak of methicillin-resistant Staphylococcus aureus (MRSA) in a large teaching hospital in The Netherlands. The commitment to bringing this outbreak under control, and by implication, the provision of the necessary resources, is impressive. In particular, those controlling the outbreak were quickly able to create an additional laboratory specifically to process MRSA screening cultures, provide a separate outpatient department for MRSA-colonized patients, isolate all new patients with MRSA colonization and/or infection, and screen nearly $100 \%$ of staff (see the Table in van Trijp et al. ${ }^{1}$ ).

In The Netherlands, MRSA infection is epidemic; outbreaks occur from time to time and they can usually be controlled and MRSA eradicated. In Ireland, the United Kingdom, and many other countries, MRSA is endemic, and management efforts largely focus on control rather than erad- 